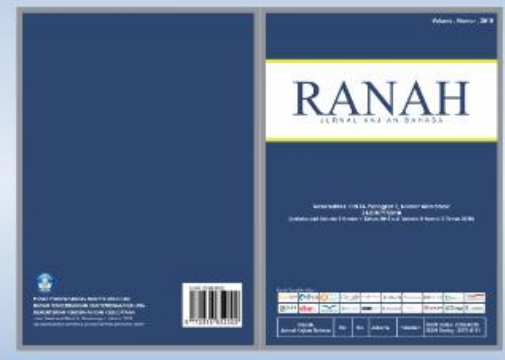

\title{
TINGKAT KESANTUNAN NONVERBAL DALAM TUTURAN VERBAL ANTARA PENJUAL DAN PEMBELI DI PASAR BERINGHARJO YOGYAKARTA: KAJIAN ETNOPRAGMATIK
}

Nonverbal Communication Politenes Levels of the Speech Act Between Sellers and Buyers in Yogyakarta Beringharjo Market: Etnopragmatics Study

\section{Pranowo}

Universitas Sanata Dharma Yogyakarta. prof.pranowo2@gmail.com doi: https://doi.org/10.26499/rnh.v9i2.2975

\begin{abstract}
Abstrak
Tingkat kesantunan nonverbal dalam tindak tutur verbal merupakan kajian etnopragmatik. Desain penelitian adalah deskripsitif kualitatif dengan teori dasar etnopragmatik. Teori etnografi pada dasarnya merupakan teori yang biasa digunakan untuk mengkaji kebudayaan suatu etnis. Dalam perkembangan selanjutnya, etnografi dapat dipakai untuk mengkaji tindak budaya, termasuk tindak tutur berbahasa. Tindak budaya dalam berbahasa tidak dapat dilepaskan dengan konteks pemakaian bahasa. Oleh karena itu, kajian ini juga melibatkan teori pragmatik. Tindak tutur budaya dapat terjadi di berbagai lingkungan peristiwa tutur. Penelitian ini akan mengkaji tindak tutur yang terjadi di lingkungan budaya Pasar Beringharjo Yogyakarta ketika pedagang-pembeli saling bertransaksi. Tujuan penelitiannya adalah (a) mendeskripsikan wujud kesantunan nonverbal yang digunakan oleh penjual-pembeli dan antarpedagang di Pasar Beringharjo, dan (b) mendeskripsikan faktor yang memengaruhi tingkat kesantunan nonverbal dalam tuturan verbal oleh penjual-pembeli.
\end{abstract}

Kata-kata kunci: bahasa verbal, bahasa nonverbal, tingkat kesantunan, dan etnopragmatik.

\begin{abstract}
The levels of nonverbal politeness in verbal speech acts is an ethnopragmatic study. The research design was descriptive qualitative with ethnopragmatic basic theory. Ethnographic theory is basically a theory commonly used to study the culture of an ethnicity. In further developments, ethnography can be used to study cultural acts, including speech acts in language. Cultural acts in language cannot be separated from the context of language usage. Therefore, this study also involves pragmatic theory. Cultural speech acts can occur in various environments of speech events. This research will examine speech acts that occur in the cultural environment of the Beringharjo market in Yogyakarta when traders and buyers transact with each other. The research objectives are (a) to describe the form of nonverbal politeness used by buyers and sellers in the Beringharjo market, and $(b)$ to describe the factors that influence the level of nonverbal politeness in verbal speech by the seller-buyer.
\end{abstract}

Key words: verbal language, nonverbal language, politeness level, and ethnopragmatic.

How to Cite: Pranowo. (2020). Tingkat Kesantunan Nonverbal dalam Tuturan Verbal antara Penjual dan Pembeli di Pasar Beringharjo Yogyakarta: Kajian Etnopragmatik. Ranah: Jurnal Kajian Bahasa. 9(2). 312-325. doi: https://doi.org/10.26499/rnh.v9i2.2975 


\section{PENDAHULUAN}

Tingkat kesantunan pada dasarnya adalah kadar kesantunan yang ditunjukkan oleh penutur ketika berkomunikasi. Kadar kesantunan dapat diidentifikasi melalui tinggi-rendahnya tingkat kesantunan berbahasa penutur. Leech memberikan gambaran tingkat kesantunan itu dengan istilah "skala kesantunan” (G. N. Leech 1983), meliputi (a) skala untung-rugi, (b) skala kemanasukaan, dan (c) skala ketidaklangsungan. Meskipun demikian, skala kesantunan yang dimaksud Leech masih terbatas pada skala kesantunan bahasa verbal. Sementara itu, tingkat kesantunan yang ditunjukkan melalui bahasa nonverbal belum disinggung. Oleh karena itu, penelitian ini di samping mendeskripsikan tingkat kesantunan dalam bahasa verbal juga mendeskripsikan tingkat kesantunan bahasa nonverbal dengan kajian etnopragmatik.

Tindak tutur verbal lisan selalu disertai dengan bahasa nonverbal ketika berkomunikasi. Bahasa nonverbal dalam berkomunikasi dapat berfungsi sebagai (a) pengganti tuturan verbal (substitusi), (b) pemberi penekanan pada bahasa verbal (aksentuasi), (c) menunjukkan pertentangan dengan bahasa verbal (kontradiksi), (d) mengulang ucapan verbal (repetisi), dan (e) melengkapi tuturan verbal (complementary) (Knapp, M. L., \& Hall 2002). Hal ini karena penggunaan bahasa lisan verbal kadang-kadang menghadapi kendala dalam berkomunikasi, seperti (a) tuturan yang mengandung ambiguitas makna yang dimaksud oleh penutur, (b) tidak dapat menangkap tuturan yang mengandung implikatur, bukan makna pragmatiknya, (c) tidak dapat dipahami ketika penutur menggunakan kata-kata deiktik yang referensinya berpindahpindah, dan (d) tidak dapat dipahami ketika penutur memiliki latar belakang budaya yang berbeda dengan mitra tutur.

Namun, bahasa nonverbal dapat juga tuturan menjadi kurang santun. Misalnya, orang bertutur verbal mengatakan "Saya tidak suka dengan orang yang tidak setia pada profesinya!". Dengan tuturan verbal seperti itu, tingkat kesantunannya wajar-wajar saja. Namun, ketika penutur menyertai dengan gerakan nonverbal memukul meja dengan keras dan matanya sambil melotot, tingkat kesantunannya justru menurun karena ekspresi seperti itu. Atas dasar uraian di atas, rumusan masalah penelitian adalah (a) wujud kesantunan nonverbal apa saja yang digunakan oleh penjual-pembeli di Pasar Beringharjo Yogyakarta dan (b) faktor apa saja yang mempengaruhi tingkat kesantunan nonverbal dalam tuturan verbal oleh penjual-pembeli di Pasar Beringharjo Yogyakarta. 


\section{LANDASAN TEORI}

Kesantunan adalah keadaan yang menggambarkan harkat dan martabat seseorang agar dapat menghargai diri sendiri dan tidak menyinggung perasaan mitra tuturnya (Pranowo 2018). Dengan demikian, ketika seorang penutur bertutur, mitra tutur tidak tersinggung atas tuturan penutur. Leech menyatakan hal yang berbeda dengan pendapat di atas. Leech menyatakan bahwa berbahasa santun adalah berbahasa yang tidak menyinggung perasaan hati mitra tutur (G. N. Leech 1983). Leech (1983) memberikan gambaran tingkat kesantunan itu dengan istilah "skala kesantunan", meliputi (a) skala untung-rugi, (b) skala kemanasukaan, dan (c) skala ketidaklangsungan. Meskipun demikian, skala kesantunan yang dimaksud Leech masih terbatas pada skala kesantunan bahasa verbal.

Robin Lakof (1973) menyatakan bahwa agar tuturan dapat dinyatakan santun harus memenuhi (a) skala formalitas dalam arti penutur tidak memaksa mitra tutur agar masingmasing saling merasa nyaman; (b) skala ketidaktegasan, dalam arti tuturan yang digunakan hendaknya saling dirasakan nyaman oleh kedua belah pihak; dan (c) skala kesekawanan, dalam arti penutur dan mitra tutur memperlihatkan sifat keramahan dan rasa persabatan.

Sebenarnya, kesantunan berbahasa bukan hanya pada kesantunan bahasa verbal tetapi juga melalui bahasa nonverbal. Berbagai gerakan nonverbal yang ikut menentukan makna pragmatik dapat pula menentukan tingat kesantunan. Ketika seorang penutur menyapa mitra tutur dengan ucapan "selamat pagi!" sambil mengulurkan tangan untuk menjabat tangan mitra tutur menandakan sikap santun penutur terhadap mitra tutur.

Di samping itu, tindak tutur adalah tindakan mengungkapkan gagasan seorang penutur kepada mitra tutur. Tindak tutur terdiri atas tiga aspek, yaitu (a) lokusi, (b) ilokusi, dan (c) perlokusi (Searle, 1974). Lokusi adalah rentetan bunyi yang membentuk satuan makna secara linguistis maupun pragmatis. Sementara itu, ilokusi adalah maksud yang ingin diungkapkan oleh penutur. Misalnya: "Barang yang Ibu jual ini bagus-bagus makanya banyak orang yang tidak berani membelinya" (ucapan pembeli sambil memegang kain yang akan dibeli sambil dikibas-kibaskan). Tuturan itu mengandung makna semantik pujian. Namun, jika ditafsir menggunakan makna pragmatik, tuturan tersebut dapat bermakna sindiran karena calon pembeli sambil mengibas-ngibaskan baju dagangan untuk mencela. Perlokusi adalah efek yang dipahami oleh mitra tutur atas tuturan si penutur. Seorang pedagang mengatakan "Harga baju ini sudah murah lho mbak, kalau dibandingkan dengan harga di toko sebelah!”. Penutur ingin membujuk pembeli agar mau membeli baju dagangannya. 
Dalam setiap tindak tutur, tuturan selalu menggunakan konteks. Istilah konteks pertama kali digunakan oleh Malinoswski (1938) dengan sebutan konteks situasi. Sementara itu, G. Leech (2014) mendefinisikan konteks adalah aspek-aspek yang berkaitan dengan lingkungan fisik dan sosial suatu tuturan. Leech menambahkan bahwa konteks sebagai pengetahuan latar belakang yang secara bersama dimiliki oleh penutur dan mitra tutur yang dapat membantu menginterpretasikan maksud penutur.

Pengertian konteks dibedakan menjadi dua, yaitu dalam arti luas dan dalam arti sempit. Dalam arti luas, konteks sebagai pengetahuan tentang faktor-faktor di luar tuturan yang dipertimbangkan dalam berkomunikasi. Dalam arti sempit, konteks adalah bagian lain dari teks sebelum atau sesudahnya (co-text). Song (2010) menyebut dengan istilah konteks linguistik.

Lebih lanjut Song mengklasifikasikan kenteks menjadi (a) konteks linguistik, (c) konteks situasi, (d) konteks sosial, dan (e) konteks budaya (Song, 2010). Sebaliknya (Huang et al. 2004) mengidentifikasi jenis konteks menjadi tiga macam, yaitu (a) konteks fisik (seperti lokasi spatio-temporal, ucapan/lokasi ruang-waktu dari tuturan, (b) konteks linguistik, dan (c) konteks pengetahuan umum.

Atas dasar pendapat di atas, studi pragmatik dapat didefinisikan sebagai studi mengenai pemakaian bahasa berdasarkan konteksnya. Deda (2013) menyatakan bahwa dalam berkomunikasi, makna yang diungkapkan meliputi makna verbal dan makna nonverbal sesuai konteksnya. Beberapa ahli mendefinisikan konteks dari sudut pandang yang berbeda-beda, tergantung permasalahan yang dihadapi masing-masing. Widdowson (1989) mendefinisikan konteks sebagai "... aspek-aspek dari keadaan penggunaan bahasa aktual yang dianggap relevan dengan makna". Cook (2003) yang mempelajari hubungan wacana dengan sastra, menyatakan bahwa konteks hanyalah sebuah bentuk pengetahuan dunia (knowledge of the world).

Berkaitan dengan bahasa nonverbal, Lapakko (2007) mendefinisikan sebagai alat ekspresi komunikasi tanpa kata-kata (bahasa isyarat: gestur, nada, tatapan muka, intonasi). Komunikasi nonverbal tidak hanya gerakan dan bahasa tubuh tetapi juga cara mengungkapkan aspek lain (perubahan nada suara, jeda, warna suara, volume, dan aksen bicara). Aspek nonverbal seperti itu mempengaruhi maksud yang ingin disampaikan penutur. Karena pentingnya komunikasi, pesan dapat disampikan melalui bahasa nonverbal, seperti (a) dapat menentukan komunikasi interpersonal, (b) perasaan dan emosi lebih tepat disampaikan melalui bahasa nonverbal, (c) bahasa verbal yang didukung bahasa nonverbal relatif bebas dari kebohongan, (d) pesan nonverbal kadang-kadang lebih efektif daripada pesan dalam bahasa 
verbal, (e) bahasa nonverbal dapat memyampaikan fungsi metakomunikatif daripada bahasa verbal, dan (f) bahasa nonverbal kadang-kadang dapat mensugesti mitra tutur secara tepat.

Wang (2014) mengklasifikasikan bahasa nonverbal menjadi 3 (tiga), yaitu (1) bahasa isyarat (seperti gestur diam, kernyitan jidat), (2) bahasa tindakan (gerakan yang dapat menyampaikan makna yang berbeda, dan (3) bahasa objek (benda yang tidak disiapkan secara sengaja, seperti barang-barang yang ada di sekitar penutur). Atas dasar pendapat Wong, peneliti membuat garis besar (outline) bahasa nonverbal yang biasa dipakai masyarakat Jawa, yaitu (a) bahasa kepala, (b) bahasa badan, dan (c) anggota badan. Di samping itu, bahasa nonverbal di luar tubuh dapat dikelompokkan menjadi (a) asosiasi tubuh, (b) tingkat sosial yang meliputi (i) tingkat intelektual, (ii) kedudukan dalam masyarakat, dan (iii) kekayaan yang dimiliki (Pranowo, 2018).

Kajian etnopragmatik merupakan gabungan dari dua disiplin ilmu, yaitu etnografi dan pragmatik. Etnografi adalah kajian yang menggambarkan kehidupan suatu masyarakat atau bangsa tertentu. Ada tiga hal yang berkaitan dengan kajian etnografi, yaitu cultural knowledge, cultural behavour, dan artifact. Dalam kaitannya dengan pemakaian bahasa nonverbal tentu yang dimaksud adalah pemaknaan setiap unsur nonverbal untuk menegaskaan bahasa verbal.

Tujuan kajian etnografi adalah untuk menganalisis kebudayaan masyarakat agar dapat memahami pandangan dan hubungannya dengan kehidupan sehari-hari. Sementara itu, kajian pragmatik adalah kajian penggunaan bahasa berdasarkan konteks pemakaiannya. Crysta (1985) mendefinisikan pragmatik sebagai cabang linguistik yang mempelajari bahasa dari sudut pandang pengguna (pilihan variasi bahasa, kendala yang mereka hadapi dalam menggunakan bahasa, dan pengaruh penggunaan bahasa terhadap peserta lain dalam suatu tindakan komunikasi). Ellis (1989) mendefinisikan pragmatik sebagai studi tentang pemahaman dan produksi bahasa melalui tindakan dalam konteks. Atas dasar uraian di atas, etnopragmatik dapat didefinisikan sebagai studi penggunaan bahasa dari sudut pandang pengguna berdasarkan latar belakang budayanya.

\section{METODE PENELITIAN}

Penetian ini tergolong jenis penelitian deskriptif kualitatif. Sumber data penelitian berupa para pedagang dan pembeli yang sedang bertransaksi jual beli di Pasar Beringharjo. Data penelitiannya adalah tuturan pedagang dan pembeli ketika mereka sedang bertransaksi di pasar. Teknik pengumpulan data yang digunakan adalah observasi, wawancara, dan teknik rekaman. 
Teknik analisis data dilakukan sebagai berikut (a) identifikasi data, (b) klasifikasi data, dan (c) interpretasi data.

\section{PEMBAHASAN}

\section{Penggunaan Bahasa Nonverbal (BN) yang Menyertai Bahasa Verbal antara Penjual (Pj) dan Pembeli ( $\mathbf{P b})$ di Pasar Beringharjo}

Ketika $\mathrm{Pj}$ menawarkan dagangan kepada $\mathrm{Pb}$ biasanya menggunakan bahasa Jawa krama alus. Misalnya, seorang Pj pakaian memanggil dengan sebutan "Den” (Raden) untuk sapaan seorang priyayi, seperti “Mangga Den, ngersakaken menapa?" (Silakan, Den mau membeli apa?”, atau setidaknya menyapa dengan “Bu, Pak, Mbak, Mas”. Pada prinsip menempatkan Pb pada posisi sopan dan terhormat. Jika Pj berjualan pakaian dan konsumennya orang Jawa dan memang ingin membeli pakaian, mereka biasanya bertanya "Kagungan sruwal kangge lare umur 15 tahun, Bu?" (Punya celana untuk anak usia 15 tahun, Bu?).

Jika barang yang diinginkan memang ada, dari situlah $\mathrm{Pj}$ dan $\mathrm{Pb}$ berlanjut tawar-menawar menggunakan bahasa Jawa. Namun, jika konsumennya bukan orang Jawa, biasanya menggunakan bahasa Indonesia dan Pj pun yang semula menggunakan bahasa Jawa kemudian beralih kode menggunakan bahasa Indonesia. Tawar-menawar terus berlanjut sampai ada kesepakatan harga atau tawar-menawar berhenti jika tidak ada kesepakatan harga. Pj lain pun juga akan memperlakukan dengan cara yang hampir sama, yaitu menempatkan $\mathrm{Pb}$ pada posisi terhormat. Bahkan, kadang-kadang disertai bahasa nonverbal.

Dalam suasana lain, jika pembeli tidak ada yang mengunjungi kiosnya, Pj biasanya mengundang orang yang sedang lewat di depan kiosnya agar mereka mau mengunjungi dagangannya. Penggunaan bahasa nonverbal yang menyertai bahasa verbal antara $\mathrm{Pj}$ dan $\mathrm{Pb}$ di Pasar Beringharjo dapat bervariasi. Ketika pada awalnya Pj menggunakan bahasa Jawa dan $\mathrm{Pb}$ juga berbahasa Jawa, mereka tetap bertahan menggunakan bahasa Jawa sambil memperlihatkan barang dagangannya kepada $\mathrm{Pb}$.

Penggunaan bahasa nonverbal yang menyertai bahasa verbal, kadang-kadang juga tergantung pada sifat $\mathrm{Pj}$. Prinsip $\mathrm{Pj}$ harus selalu sumeh (murah senyum) dan tuna satak bathi sanak (rugi seikat uang, tetapi mendapat pelangan) selalu dipegang teguh oleh $\mathrm{Pj}$. Meskipun manifestasinya berbeda-beda. Perhatikan data berikut.

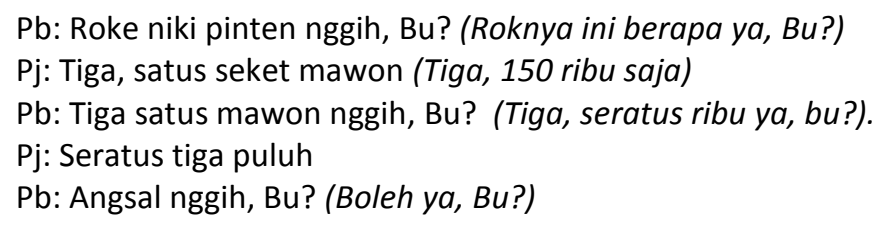


$\mathrm{Pj}$ : Seratus tiga puluh mawon, pun (Seratus tiga puluh ribu saja, lah)

$\mathrm{Pb}$ : satus limalas, telu wis. Yen ra entuk, ya wis! (Seratus lima belas ribu, tiga biji lah. Jika tidak boleh, ya sudah)

$\mathrm{Pj}$ : Ya wis, mrenea, mbak! (Ya sudah, ke sini!)

BN : Pb memegang barang yang diinginkaan, dan terus merengek agar tawarannya dikabulkan. Pj juga menunjukkan barang lain agar $\mathrm{Pb}$ tidak segera pergi.

Konteks: Pj lebih tua usianya, sedang Pb lebih muda tetapi berusaha keras menawar rok dan celana kepada penjual. Akhirnya terjadi kesepakatan harga, meskipun penjual agak cemberut pembeli senyum-senyum.

$\mathrm{Pb}$ bertanya harga rok dan celana kepada $\mathrm{Pj}$ menggunakan bahasa Jawa kromo. Karena $\mathrm{Pb}$ lebih muda usianya, Pj menjawab dengan bahasa Jawa (BJ) krama andhap campur ngoko dan bahasa Indonesia. Meskipun tawar-menawar agak alot, akhirnya terjadi kesepakatan harga. Tampaknya Pb berasal dari Yogyakarta sehingga mengetahui taktik untuk menawar dengan bahasa tetap santun sehingga mendapat harga murah. Bahasa yang digunakan $\mathrm{Pb}$ adalah bahasa nonverbal dengan terus tersenyum.

Suasana lain terjadi ketika ada $\mathrm{Pb}$ yang masih agak ragu-ragu. Suasana seperti itu terjadi ketika ada $\mathrm{Pb}$ yang belum jelas mau belanja apa. $\mathrm{Pj}$ mencoba mengundang agar $\mathrm{Pb}$ mau singgah di kios dagangannya, siapa tahu mereka mau menjadi konsumennya. Hanya dengan gerakan tubuh (gestur) tanpa mengatakan "ya" atau "tidak" $\mathrm{Pb}$ pun berkenan mampir sambil melihatlihat barang. Undangan $\mathrm{Pj}$ ternyata berhasil. $\mathrm{Pb}$ mau mampir ke kiosnya, bahkan $\mathrm{Pb}$ menanyakan sesuatu kepada Pj. Perhatikan data di bawah ini.

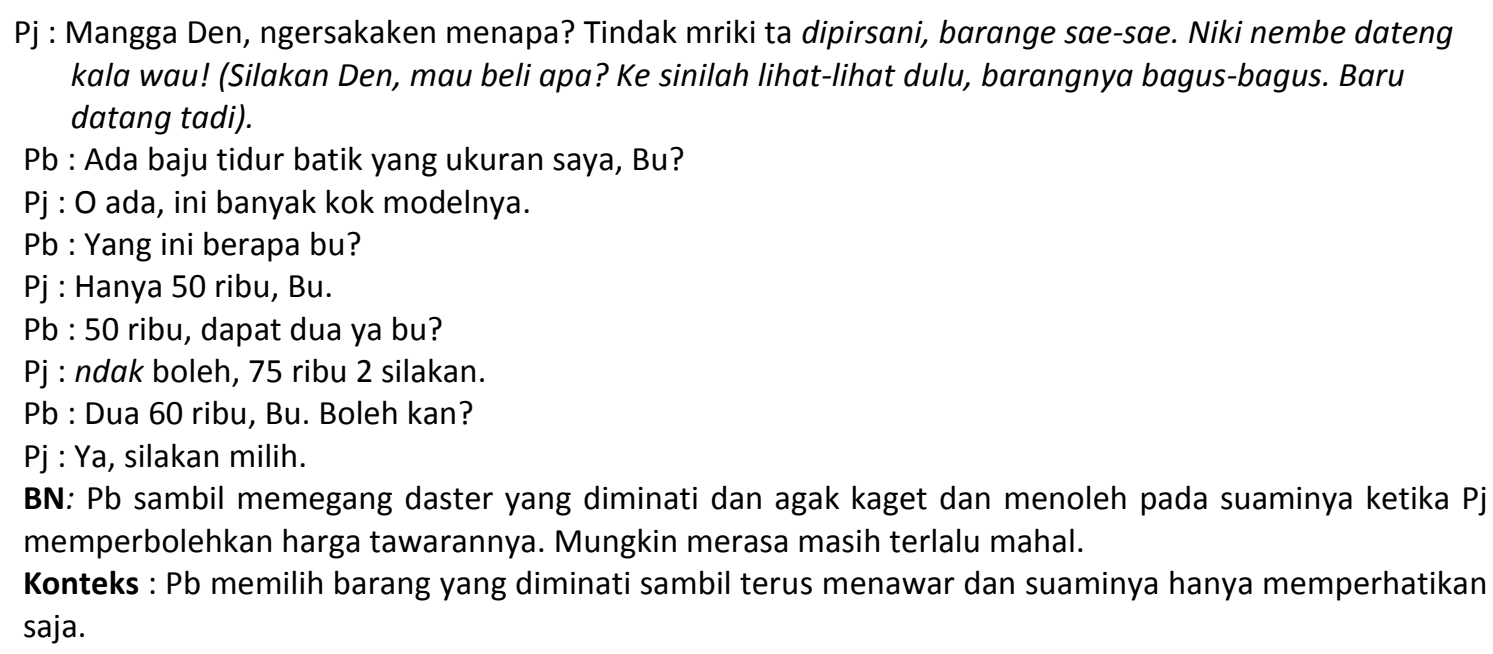

$\mathrm{Pb}$ terus memilih baju, sambil bertanya "ada baju tidur, Bu?”. Pj menunjukkan contoh baju tidur berbahan batik dan $\mathrm{Pb}$ menanyakan harganya. Ketika tawaran dikabulkan oleh $\mathrm{Pj}$, justru $\mathrm{Pb}$ agak terkejut dan menoleh memandangi suaminya. Barang kali, $\mathrm{Pb}$ menduga bahwa harga yang disepakati masih terlalu mahal. 
Lain halnya dengan suasana tawar-menawar $\mathrm{Pb}$ dan $\mathrm{Pj}$ sayur-sayuran. $\mathrm{Pb}$ belum bertanya harga sayur terong, tetapi sudah menentukan harga sendiri dua ribu sekilo. Bahkan, $\mathrm{Pb}$ sambil berkomentar "saiki lagi murah, ta" (sekarang lagi murah, kan). Perhatikan data di bawah ini.

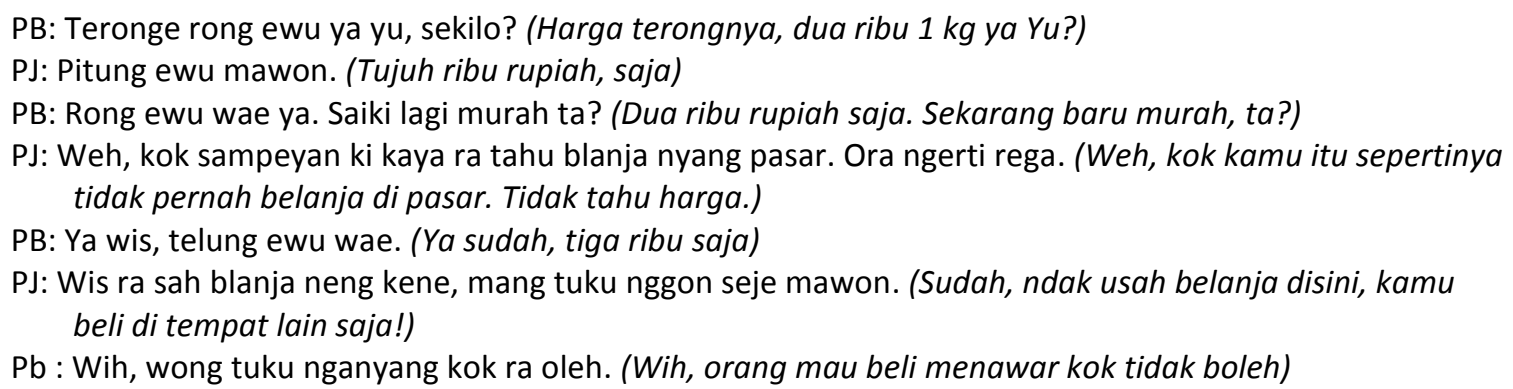

Tawar-menawar $\mathrm{Pb}$ dan $\mathrm{Pj}$ sejak awal sudah tidak kondusif. $\mathrm{Pb}$ memperlakukan $\mathrm{Pj}$ dalam posisi rendah dengan BJ ngoko "Teronge sekilo pira, Yu" (Terongnya sekilo berapa, Yu?). Apa lagi setelah menawar dagangan dengan menyebut "Rong ewu wae ya. Saiki lagi murah ta?" (Dua ribu saja ya. Sekarang kan lagi murah.). Dengan tawaran seperti itu, Pj menjadi sangat tersinggung kemudian menjawab "Wah, kok sampeyan ki kaya ra tahu blanja nyang pasar. Ora ngerti rega." (Wah, kok Anda itu Nampak seperti tidak pernah belanja di pasar. Tidak tahu harga.). Pj yang semula berbicara santun, kemudian berubah menjadi tidak santun. Pj menyapa $\mathrm{Pb}$ dengan kata-kata ngoko "Ora ngerti rega", atau ngoko andhap dengan sapaan "sampeyan", "mboten oleh", sambil mengalihkan pandangan pada $\mathrm{Pb}$ lain.

Transaksi jual-beli yang relatif tidak ada tawar-menawar harga adalah penjual makanan "oprokan" atau Pj pasar keliling. Harga barang yang dijual relatif murah dan $\mathrm{Pb}$ biasanya berbelanja untuk “oleh-oleh" keluarganya. Perhatikan data berikut ini.

$\mathrm{Pb}$ : Satene pintenan, Bu? (Satenya berapaan, Bu?)

$\mathrm{Pj}$ : Gangsal ewu, sekawan (Lima ribu dapat empat)

$\mathrm{Pb}$ : Pun sak lonthonge niku? (Termasuk lontongnya itu?)

$\mathrm{Pj}$ : Lonthonge setunggal, sewu gangsal atus (Lontongnya satu harganya seribu lima ratus)

$\mathrm{Pb}$ : Bungkuske satene wolu, lonthonge kalih nggih, Bu.Didadoske kalih bungkus! (Bungkuskan satenya delapan, lontongnya dua ya, Bu. Jadikan dua bungkus!)

BN : Pj terus berbicara melayani Pb sambil ngipasi sate yang sedang dibakar.

Konteks : Pj biasanya menyajikan dagangannya berjajar dengan Pj lain sehingga tidak terjadi tawar-menawar karena banyak saingannya. Pj lain sekaligus menjadi kontrol sosial bagi dirinya.

Pj makanan oprokan biasanya tidak membawa banyak dagangan. Mereka biasanya hanya mengambil dagangan dari produsen dan menjual keliling pasar. Upah yang diterima Pj sudah ditentukan oleh produsen sehingga $\mathrm{Pj}$ tidak berani menaikkan atau menurunkan harga. Jika $\mathrm{Pb}$ 
menawar harga, biasanya hanya pura-pura menawar tetapi sesunggunya punya perasaan iba pada $\mathrm{Pj}$.

Bahkan, ada $\mathrm{Pj}$ dan $\mathrm{Pb}$ yang tidak pernah terjadi tawar-menawar harga yaitu $\mathrm{Pj}$ kuliner yang dimakan di tempat berjualan. Pb pada umumnya datang dan duduk, kemudian meminta jenis makanan atau minuman yang diinginkan. Mata dagangan yang dijual sesuai dengan yang ada di hadapan $\mathrm{Pj}$, sementara $\mathrm{Pb}$ juga sudah mengetahui jenis makanan yang dijual. Perhatikan BN dan tuturan verbal di bawah ini.

$\mathrm{Pj}$ : Mau makan apa, Mas? Bungkus atau makan disini?

$\mathrm{Pb}$ : Makan di sini aja, kasih ayam dan minum teh manis ya, Bu!

$\mathrm{Pj}:$ Ya, sebentar ya!

$\mathrm{Pb}$ : Tadi teman saya yang kemarin makan di sini sudah ke sini apa belum, Bu?

$\mathrm{Pj}$ : Sudah jam 11 tadi, katanya mau pulang kampung karena ada saudaranya yang hajatan. Gitu, Mas.

$\mathrm{BN}$ : Meskipun antrean agak banyak, bagi Pb yang mau makan di tempat atau konsumennya pria, biasanya kalau di pasar dilayani lebih dulu. Di sini tidak pernah ada tawar-menawar harga.

Konteks: Hubungan Pj dan Pb sudah akrab karena sebagai pelanggaan dan kadang-kadang ada yang sudah titip uang untuk jatah makan sebulan. Namun, ada juga yang tidak titip uang tetai tetap makan. Mereka ini disebut "ngebon".

Biasanya ketika $\mathrm{Pb}$ sedang makan, $\mathrm{Pj}$ mengajak ngobrol tentang suasana asal desanya atau teman-teman mereka. Setelah selesai makan, $\mathrm{Pb}$ membayar sesuai dengan harga yang sudah dimakan. Namun, ketika peneliti sedang mengumpulkan data (sambil ikut makan sekaligus), ada $\mathrm{Pb}$ yang tidak membayar, tetapi hanya mencatat dalam buku catatan. Tampaknya, $\mathrm{Pb}$ sudah berlangganan dan sudah menitipkan uang untuk jatah 1 bulan. Sebaliknya, ada $\mathrm{Pb}$ yang juga mencatat menu yang dimakan, tetapi belum menitipkan uang, alias "ngebon". Hal demikian sudah biasa bagi $\mathrm{Pb}$ yang telah lama menjadi langganannya.

\section{Faktor yang menyebabkan bergesernya tingkat kesantunan Pj dan Pb ketika terjadi tawar-menawar di Pasar Beringharjo}

Banyak faktor yang menyebabkan terjadinya pergeseran tingkat kesantunan $\mathrm{BN}$ yang menyertai bahasa verbal antara $\mathrm{Pj}$ dan $\mathrm{Pb}$ dalam tawar-menawar harga di Pasar Beringharjo. Tindak tawar-menawar yang paling rendah (tidak ada tawar-menawar) adalah pedagang makanan warungan dan tingkat kesantunannya paling tinggi. Antara $\mathrm{Pj}$ dan $\mathrm{Pb}$ tidak pernah melakukan tawar-menawar di Pasar Beringharjo. Faktor penyabanya adalah (a) persepsi $\mathrm{Pb}$ terhadap makanan berkaitan dengan kesopanan, (b) Pj pada umumnya di pasar Beringharjo mematok harga wajar, (c) harga bahan mentah dengan harga makanan jadi relatif jelas kriterianya, yaitu 1:3. Artinya, satuan harga bahan mentah jika dijual menjadi 3 kali lipat karena harus mengolah dan menjajakan. 
Tindak tawar-menawar penjaja makanan gendongan relatif rendah karena semua barang yang dijual hanyalah menjualkan milik produsen sambil berkeliling pasar untuk menemui $\mathrm{Pb}$. Faktor yang menjadi penyebab, antara lain (1) $\mathrm{Pj}$ hanya menjualkan milik produsen yang sudah ditentukan harganya, (2) $\mathrm{Pb}$ tidak tega menawar karena mereka biasanya bermodal kecil, dan (3) $\mathrm{Pj}$ memiliki pelanggan $\mathrm{Pb}$ tetap.

Tindak tawar-menawar $\mathrm{Pj}$ buah masih terjadi penawaran, tetapi tawar-menawarnya relatif sedang. Biasanya menawar hanya satu dua kali dan asal buah yang akan dibeli sesuai dengan keinginan $\mathrm{Pb}$ maka titik kesepakatan harga terjadi. Faktor penyebab terjadinya tawar-menawar harga buah adalah (1) $\mathrm{Pb}$ sudah biasa membeli di kios-kios di luar pasar sehingga sudah tahu harganya, (2) $\mathrm{Pb}$ tahu bahwa penjual buah di pasar tidak memiliki dagangan yang variatif, dan (3) $\mathrm{Pj}$ tidak pernah berselisih paham dengan $\mathrm{Pb}$.

Tindak tawar-menawar cukup tinggi adalah $\mathrm{Pj}$ dan $\mathrm{Pb}$ sayur-mayur. $\mathrm{Pj}$ sebenarnya tidak pernah mematok harga terlalu tinggi, tetapi kadang-kadang $\mathrm{Pb}$ masih menawar dengan harga sangat rendah, seperti “Rong ewu wae ya. Saiki lagi murah ta?”. Dengan penawaran seperti itu, $\mathrm{Pj}$ menjadi tersinggung dan salah paham. Kata-kata yang diucapkan oleh $\mathrm{Pj}$ pun menjadi sangat kasar dan yang semula menggunakan bahasa Jawa krama, berubah menjadi bahasa Jawa ngoko andhap, seperti “Weh, kok sampeyan ki kaya ra tahu blanja nyang pasar. Ora ngerti rega.". Karena barang dagangan ditawar dengan harga yang sangat rendah, Pj menjadi sangat tersinggung, Pj akhirnya memutuskan dibeli sesuai dengan harga yang ditawarkan pun tidak boleh "Wis ra sah blanja neng kene, tukuwa nggon seje wae". Faktor penyebab terjadinya pergeseran tingkat kesantunan adalah (1) tingkat pendidkkan Pj sayur pada umumnya rendah dan bermodalkan kecil, (2) $\mathrm{Pj}$ mudah tersinggung dengan penawaran $\mathrm{Pb}$, dan (3) sikap $\mathrm{Pb}$ terhadap Pj sayur cenderung meremehkan. Dengan demikian, tingkat kesantunan BN dan verbal sangat rendah.

\section{Penggunaan BN yang Menyertai Bahasa Verbal antara Pj dan Pb di Pasar Beringharjo}

Jika tawar-menawar harga barang di samping menggunakan bahasa verbal, baik $\mathrm{Pj}$ maupun $\mathrm{Pb}$ juga menggunakan $\mathrm{BN}$. Penggunaan $\mathrm{BN}$ yang menyertai bahasa verbal sejalan dengan yang dikemukakan oleh (Argyle 1972) yang menyatakan bahwa ada tiga bentuk komunikasi bahasa nonverbal yaitu (1) komunikasi bahasa nonverbal sikap, emosi, manipulasi, dan situasi langsung, (2) komunikasi bahasa nonverbal sebagai pendukung dan pelengkap komunikasi verbal, dan (3) komunikasi bahasa nonverbal sebagai pengganti bahasa verbal. 
Penggunaan BN yang menyertai bahasa verbal para $\mathrm{Pj}$ dan $\mathrm{Pb}$ di Pasar Beringharjo juga menunjukkan bahwa sikap PJ dan Pb bervariasi. Ketika sedang terjadi tindak tawar-menawar, ada yang bersikap sangat santun, santun, dan tidak santun. Para Pj warungan dan penjual jajanan gendong berada pada tingkat kesantunan yang paling tinggi karena tidak terjadi tawarmenawar. Sementara itu, tindak tawar-menawar paling alot adalah penjual pakaian, tindak tawar-menawar pakaian jadi, karena $\mathrm{Pj}$ cenderung menawarkan harga tinggi, sementara $\mathrm{Pj}$ telah memahami bahwa $\mathrm{Pb}$ di Pasar Beringharjo pasti menawar separuh harga atau bahkan kurang yang diminta $\mathrm{Pj}$. Namun demikian, Tarik-ulur harga itu justru menjadi seni tersendiri bagi $\mathrm{Pb}$ dan bila berhasil mereka sangat puas. Meskipun demikian, tingkat kesantunannya tetap terjaga denngan baik.

Tawar-menawar yang paling menyedihkan adalah Pj sayur-mayur. Persepsi awal, ada $\mathrm{Pb}$ yang memandang rendah terhadap $\mathrm{Pj}$ sayur. Ketika akan berbelanja, Pb belum menanyakan harga, tetapi telah menentukan sendiri harga barang yang akan dibeli, misalnya "Teronge sekilo rong ewu wae ya, Yu. Saiki kan lagi murah.” . Cara calon $\mathrm{Pb}$ seperti itu sangat menyinggung perasan $\mathrm{Pj}$ karena merasa dilecehkan. $\mathrm{Pb}$ bertutur menggunakan $\mathrm{BJ}$ ngoko padahal sama-sama dewasa dan belum saling mengenal. Karena ketersinggungan $\mathrm{Pj}$, kemudian $\mathrm{Pj}$ mengatakan “Weh, kok sampeyan ki kaya ra tahu blanja nyang pasar wae. Ora ngerti rega.”. Emosi Pj naik dan sampai mengatakan “Wis ra sah blanja na kene wae, mang tuku nggon seje.”. Komunikasi seperti itu melanggar kesantunan berdagang karena menghindari kudu sumeh (selalu senyum) dan "tuna satak, bathi sanak" (rugi sedikit uang tetapi mendapat saudara atau relasi "untuk pelanggan').

Hal lain yang perlu diperhatikan adalah maksim kesantunan yang dikemukakan oleh Lech bahwa BN dengan menunjukkan sikap rendah hati $\mathrm{Pj}$ terhadap $\mathrm{Pb}$ adalah menempatkan $\mathrm{Pb}$ pada posisi terhormat. Sapaan Pj terhadap Pb dengan sebutan "Mangga Den, mangga Mbak, mangga Mas, mangga Bu" selaras dengan maksim kerendahan hati yang dikemukakan oleh Leech (1982). Bukan hanya itu, Pj harus memiliki kompetensi sikap hormat kepada $\mathrm{Pb}$.

Sikap Pj yang harus dihindari adalah mudah tersinggung. Seperti data di atas yang berkaitan dengan Pj sayur-mayur secara logika tidak salah karena merasa dilecehkan menjadi tersinggung. Namun, bagi seorang pedagang hal seperti itu tidak produktif dalam berbisnis. Orang sabar ketika bertutur di samping bener 'benar' juga harus pener 'tepat'. Oleh karena itu, pedagang tidak boleh salah dalam menyikapi $\mathrm{Pb}$. Biarlah $\mathrm{Pb}$ melecehkan, tetapi jika Pj tetap bertahan dan malah memuji $\mathrm{Pb}$ justru akan lebih diuntungkan. Hal itulah prinsip bijaksana yang dimaksud Grice (Grice 1975). 


\section{Faktor yang menyebabkan bergesernya tingkat kesantunan $\mathrm{Pj}$ dan Pb ketika terjadi tawar-menawar di Pasar Beringharjo}

Tingkat kesantunan BN bukan barang mati, tetapi dapat bergeser atau berubah sesuai dengan kondisi zaman. Di zaman dahulu, orang Jawa makan sambil berdiri dianggap tidak santun karena anjing saja ketika makan bisa duduk. Namun, dalam perkembangan selanjutnya, setelah dengan alasan demi efisiensi, efektivitas, dan keakraban pertemanan, setelah orang barat mengadakan standing party, justru orang Indonesia merasa tertinggal. Pesta sambil duduk dua jam dianggap tidak efisien dan tidak dapat berakrab-akrab dengan sahabat, kolega, dan saudara.

Berkaitan dengan hal seperti itu, tingkat kesantunan tawar-menawar di Pasar Tradisional Beringharjo apakah juga akan bergeser mengikuti perubahan zaman. Namun, realitanya tidak seperti itu. Di Yogyakarta sudah banyak berdiri toko swalayan, masyarakat Yogyakarta masih banyak yang datang ke Pasar Beringharjo untuk berbelanja. Setiap hari (sebelum ditutup sementara karena covid-19), Pasar Beringharj0 dikunjungi 16.000 orang setiap harinya. Hal ini membuktikan ada daya tarik tersendiri bagi para pengunjung pasar.

Jika demikian, tampaknya identifikasi faktor peyebab bergesernya nilai kesantunan nonverbal yang menyertai bahasa verbal dalam tawar-menawar untuk mencapai kesepakatan harga masih relevan dengan kondisi sosial budaya masyarakat Yogyakarta pada khususnya atau bahkan masyarakat Nusantara pada umumnya.

Di samping itu, ekspresi wajah sebagai salah satu wujud BN yang paling produktif memperlihatkan $\mathrm{BN}$ adalah merupakan keinginan berekspresi secara bersemuka (face to face) dengan orang lain yang dekat hubungannya, dikenal secara pribadi, merindukan pertemuan kesamaan budaya merupakan pertanda bahwa tingkat kesantunan masih relatif sama seperti dahulu (bandingkan dengan kajian Kusumawati, 2016). Dengan demikian, ketika ada pertemuan bersemuka merupakan manifestasi BN otentik, tidak sekedar manifestasi semu, seperti dalam film atau sinetron.

Tindak tawar-menawar dalam BN dan bahasa verbal yang dipandang santun dan tetap masih dijunjung tinggi adalah masalah makan. Di pasar tradisional maupun di restoran tidak ada yang "jajan" menawar harga makanan. Hal ini karena masalah urusan perut dianggap tidak sopan kalau tawar-menawar. Di samping itu, harga makanan di warung pasar tradisional harganya memang bagi $\mathrm{Pb}$ masih sangat terjangkau dan $\mathrm{Pj}$ masih mendapat untung.

Kesantunan nonverbal dalam bahasa verbal yang juga masih cukup terjaga adalah $\mathrm{Pj}$ sembako. Pj sembako masih terjadi tawar-menawar, tetapi tingkat kesantunannya masih tetap terjaga dengan baik. Faktor penyebabnya adalah harga sembako telah ditentukan dari produsen 
sehingga mengambil untung sedikit saja masih beruntung. Apalagi jika jumlah butir mata dagagannya banyak tentu untuk mengejar untung tidak perlu bersikeras dengan $\mathrm{Pb}$. Sikap bijaksana dan rendah hati sebagai Pj tetap dapat dijaga dengan baik (G. Leech, 2014).

Tindak tawar-menawar yang masih cukup tetap terjaga kesantunannya adalah Pj pakaian jadi. Harga pakaian jadi biasanya dibeli oleh $\mathrm{Pj}$ melalui kulakan dalam jumlah grosiran. Sebenarnya, $\mathrm{Pb}$ menawar dengan harga 50\% dari penjual pun sudah beruntung. Maka dari itu, Pj cukup santai ketika tawar-menawar. Pj pakaian jadi kadang-kadang justru dapat membantu $\mathrm{Pb}$ untuk mengarahkan pilihan barang yang berkualitas. Dengan demikian, ketika berhadapan dengan $\mathrm{Pb}$ tidak lagi mengejar untung besar. Dari situlah sikap bijaksana penjual masih nampak di Pasar Tradisional Beringharjo (G. Leech, 2014).

Hal yang perlu dihindari dalam tindak tawar-menawar $\mathrm{PJ}$ dengan $\mathrm{Pb}$ adalah mudah tersinggung dengan $\mathrm{Pb}$ seperti yang terjadi pada pedagang sayur-mayur. Betapa pun tersinggungnya $\mathrm{Pj}$ terhadap pembeli, entah merasa karena dilecehkan atau tidak dihargai, $\mathrm{Pj}$ harus tetap bersikaap rendah hati terhadap $\mathrm{Pb}$. Sikap yang perlu ditumbuhkan kepada $\mathrm{Pj}$ adalah melayani Pb dengan tetap rendah hati (G. Leech, 2014).

\section{PENUTUP}

Berdasarkan hasil analisis dan pembahasan di atas dapat disimpulkan sebagai berikut. Pertama, tingkat kesantunan nonverbal dalam tuturan verbal dalam tindak tawar-menawar pada umumnya masih berada pada tingkat santun. Pj yang berbudaya Jawa masih memegang prinsip berdagang sumeh (murah senyum), dan tuna satak, bathi sanak (rugi sedikit uang tetapi mendapat saudara/relasi baru). Tindak tawar-menawar didukung tindakan BN sebagai konteks bahasa verbal berupa (a) gerakan tangan menunjuk jenis barang, (b) memegang barang yang akan dibeli, (c) sama-sama jongkok karena Pj tidak memiliki lapak, dan (d) mengerling barang yang belum ditunjukan oleh $\mathrm{Pj}$. Meskipun demikian, ada $\mathrm{Pj}$ yang mudah tersinggung oleh $\mathrm{Pb}$ sehingga dapat mengganggu tradisi tawar-menawar di Pasar Beringharjo yang sudah menjadi ikon pariwisata Yogyakarta.

Kedua, faktor penyebab terjadinya pergeseran kesantunan, antara lain (a) para pedagang yang memiliki kios sudah semakin banyak dan hidup berkecukupan karena banyaknya mata dagangan yang dijual, (b) latar belakang pendidikan para $\mathrm{Pj}$ juga sudah lebih baik, (c) $\mathrm{Pj}$ (terutama pakaian jadi dan sembako) kebanyakan berasal dari produk pabrikan sehingga kesenjangan harga transaksional tidak terlalu mencolok, (d) tingkat persaingan cukup tinggi karena pedagang sejenis dikumpulkan menjadi satu kelompok, (e) Pasar Beringharjo masih 
tetap sebagai pasar tradisonal dengan masih memegang teguh pada kearifan lokal, dan (f) masih banyak Pj yang belum cukup memiliki modal untuk usaha yang lebih baik.

\section{DAFTAR PUSTAKA}

Argyle, M. (1972). Nonverbal Communication in Human Social Interaction. In. R. A. Hindie, Nonverbal Communication. Oxford: Cambridge University Press.

Cook, Guy. (2003). Applied Linguistics (Oxford Introduction to Language Study Series). Oxfords.

Deda, Nivis. (2013). The Role of Pragmatics in English Language Teaching. Pragmatic Competence. Academic Journal of Interdisciplinary Studies 2(4): 63-70. https://doi.org/10.5901/ajis.2012.v2n4p63

Ellis, Rod. (1989). Second Language Learning and Second Language Learners: Growth and Diversity. TESL Canada Journal 7 (1): 74. https://doi.org/10.18806/tesl.v7i1.562

Grice, H.P. (1975). Logic and Conversation. Dalam Cole; P \& J.L. Morgan. Syntax and Semantics 3 New York: Akademic Press.

Huang, Weihe, Delambo David A., Ricky Kot, Ineko Ito, Henry Long, and Karen Dunn. (2004). Journal of Ethnic And Cultural Diversity in Social Work Perspectives of Bilingual Social Workers Perspectives of Bilingual Social Workers: You Just Have to Do a Lot More for Them. Journal of Ethnic and Cultural Diversity in Social Work 13(1): 1-18. https://doi.org/10.1300/J051v13n01 04

Knapp, M. L., \& Hall, J. A. (2002). Nonverbal Communication in Human Interaction. Crawfordsville: Thomson Learning.

Kusumawati, Tri Indah. (2016). Komunikasi Verbal dan Nonverbal. Komunikas. 4(2): 145. http://download.garuda.ristekdikti.go.id/article.php?article=849809\&val=13295\&title=KOMU NIKASI VERBAL DAN NONVERBAL.

Lapakko, David. (2007). Communication Is 93\% Nonverbal: An Urban Legend Proliferates. Communication and Theater Association of Minnesota Journal. 34(2): 7-19. http://cornerstone.lib.mnsu.edu/ctamj

Leech., Geoffrey. (2014). The Pragmatics of Politeness. In Book Section, Pp. xvi, 343. https://doi.org/10.1093/acprof:oso/9780195341386.001.0001

Leech, Geoffrey Neil. (1983). Principles of Pragmatics. Harlow: Longman.

Song, Lichao. (2010). The Role of Context in Discourse Analysis. Journal of Language Teaching and Research. 1(6). https://doi.org/10.4304/iltr.1.6.876-879

Wang, Haiyan. (2014). Nonverbal Communication and the Effect on Interpersonal Communication. Asian Social Science 5(11): 155-59. https://doi.org/10.5539/ass.v5n11p155

Widdowson, H. G. (1989). Knowledge of Language and Ability for Use. Applied Linguistics 10(2). https://doi.org/10.1093/applin/10.2.128 